\title{
Adenine methylation may contribute to endosymbiont selection in a clonal aphid population
}

Victoria Reingold ${ }^{1,2}$, Neta Luria ${ }^{2}$, Alain Robichon ${ }^{1}$ and Aviv Dombrovsky ${ }^{1,2^{*}}$

\begin{abstract}
Background: The pea aphid Acyrthosiphon pisum has two modes of reproduction: parthenogenetic during the spring and summer and sexual in autumn. This ability to alternate between reproductive modes and the emergence of clonal populations under favorable conditions make this organism an interesting model for genetic and epigenetic studies. The pea aphid hosts different types of endosymbiotic bacteria within bacteriocytes which help the aphids survive and adapt to new environmental conditions and habitats. The obligate endosymbiont Buchnera aphidicola has a drastically reduced and stable genome, whereas facultative endosymbionts such as Regiella insecticola have large and dynamic genomes due to phages, mobile elements and high levels of genetic recombination. In previous work, selection toward cold adaptation resulted in the appearance of parthenogenetic A. pisum individuals characterized by heavier weights and remarkable green pigmentation.

Results: Six adenine-methylated DNA fragments were isolated from genomic DNA (gDNA) extracted from the cold-induced green variant of A. pisum using deoxyadenosine methylase (Dam) by digesting the gDNA with the restriction enzymes Dpnl and Dpnll, which recognize the methylated and unmethylated GATC sites, respectively. The six resultant fragments did not match any sequence in the A. pisum or Buchnera genomes, implying that they came from facultative endosymbionts. The A1 fragment encoding a putative transposase and the A6 fragment encoding a putative helicase were selected for further comparison between the two A. pisum variants (green and orange) based on Dam analysis followed by PCR amplification. An association between adenine methylation and the two A. pisum variants was demonstrated by higher adenine methylation levels on both genes in the green variant as compared to the orange one.

Conclusion: Temperature selection may affect the secondary endosymbiont and the sensitive Dam involved in the survival and adaptation of aphids to cold temperatures. There is a high degree of adenine methylation at the GATC sites of the endosymbiont genes at $8^{\circ} \mathrm{C}$, an effect that disappears at $22^{\circ} \mathrm{C}$. We suggest that endosymbionts can be modified or selected to increase host fitness under unfavorable climatic conditions, and that the phenotype of the newly adapted aphids can be inherited.
\end{abstract}

Keywords: Acyrthosiphon pisum, Bacteriocyte, Facultative/secondary bacterium, Epigenetic, Deoxyadenosine methylase (Dam)

\footnotetext{
* Correspondence: aviv@agri.gov.il

'INRA/CNRS/UNSA University Nice Sophia Antipolis, 400 routes de Chappes, BP 167, Sophia Antipolis 06903, France

${ }^{2}$ Department of Plant Pathology, ARO, The Volcani Center, Bet Dagan 50250, Israel
}

\section{( Biomed Central}

(c) 2014 Reingold et al.; licensee BioMed Central Ltd. This is an Open Access article distributed under the terms of the Creative Commons Attribution License (http://creativecommons.org/licenses/by/4.0), which permits unrestricted use, distribution, and reproduction in any medium, provided the original work is properly credited. The Creative Commons Public Domain Dedication waiver (http://creativecommons.org/publicdomain/zero/1.0/) applies to the data made available in this article, unless otherwise stated. 


\section{Background}

Due to their ability to alternate between sexual and parthenogenetic (asexual) modes of reproduction, their wing polyphenism and the complex relationship between their primary and secondary endosymbiotic bacteria, aphids have become an increasingly popular insect model for genomic, epigenetic, ecological, developmental and evolutionary studies. Complete genome sequences have become available for these insects, starting with the pea aphid Acyrthosiphon pisum [1,2]. Moreover, the ability to generate a repertoire of variants with distinct behavioral and physiological traits within clonal (asexual) reproduction plays an important role in epigenetic studies $[3,4]$.

The pea aphid hosts different types of endosymbiotic bacteria within bacteriocytes that help it survive and adapt to new environmental conditions and habitats. Embryonic aphids acquire endosymbionts from their mothers before birth (viviparous) via a vertical-transfer mechanism $[5,6]$. The primary endosymbiotic bacterium (Buchnera aphidicola) engages in obligate symbiosis with A. pisum [7-9], expressing crucial genes for the biosynthesis of essential amino acids (i.e., methionine, cysteine and tryptophan [9-11]); it also plays a role in aphid growth and reproduction [5,12-14]. Due to its long host adaptation and suitability, the B. aphidicola genome is remarkably stable. There does not appear to have been any chromosome rearrangements or new gene acquisitions in the last 50 to 70 million years. The B. aphidicola genome is also characterized by a highly conserved gene order and is drastically reduced in size [10], contains only essential genes, that is, minimal regulatory proteins and almost no mobile elements. Therefore, it is no longer a source of new functional genes for adaptation of its host [15]. In contrast, the secondary endosymbionts are facultative bacteria that can provide the aphid host with resistance against fungal pathogens and parasites [16,17], heat adaptation [18], host-plant specialization [19], manipulation of wing polyphenism under crowded conditions [20,21], and delayed sexual development [22]. These secondary endosymbionts might induce morphological changes such as green pigmentation [23] and complete the nutritional role of the primary endosymbiont ([24], reviewed in [11]).

In contrast to the primary endosymbiont, the secondary endosymbionts usually contain large genomes, sometimes with phages and mobile elements, and exhibit higher rates of genetic recombination and mutation [13,25]. For example, genomes of Regiella species, a known secondary endosymbiont, are similar in size to those of free-living bacteria, harbor active phages and plasmids, contain mobile elements and exhibit gene rearrangements [26].

The plasticity of the bacterial genome contributes to these microbes' fascinating adaptation to various ecological niches and dramatic changes in the environment. A significant portion of the variability of the bacterial genome is due to transposable DNA elements [27], transposon movement, transposases, and accessory genes taken from hosts [28,29], accompanied by the introduction of external chromosomal DNA (e.g., plasmids or phages) into the bacterium's genome $[29,30]$. These genomic changes play a crucial role in generating a broad spectrum of phenotypes [29] and may be associated with the adaptation of bacteria to their host-dependent lifestyle $[13,25]$.

A selection process for individual aphids adapted to a colder environment was carried out in our laboratory. This process generated two pea aphid variants: those exhibiting the typical orange pigmentation under optimal conditions $\left(22^{\circ} \mathrm{C}\right)$ and those with unique green abdomen pigmentation at colder temperatures $\left(8^{\circ} \mathrm{C}\right)[3,31]$.

To date, there have been no reports on how endosymbionts might affect the epigenetic state (e.g., gene expression, DNA or histone modifications) of aphid genomes. The aim of this study was to investigate the role of endosymbionts in the phenotypic adaptation of aphids to unfavorable temperature conditions. We hypothesized that selection of a particular strain(s) of secondary endosymbiont and genome modifications such as adenine methylation might contribute to the adaptation of the selected aphid variant and cause phenotypic changes.

\section{Results}

Selection of an aphid variant with a unique pigmentation In a previous study, selection for cold adaptation was performed by keeping ten orange adult aphids at $10^{\circ} \mathrm{C}$ for two days. After five months of this selection, we had obtained a viable and robust colony of green variants. To stabilize the cold-induced green variants, the selection pressure was increased in two steps: (1) the aphid population was propagated at $9^{\circ} \mathrm{C}$ for 1 year and (2) the temperature was then lowered to $8^{\circ} \mathrm{C}$ for continuous propagation (for 5 years; summarized in Figure 1).

The emerged green variants of $A$. pisum were characterized by a longer life cycle and slightly bigger bodies during the adult stage, with a heavier average weight [1.12 $\mathrm{mg}$ and $1.416 \mathrm{mg}$ for the green adults (winged versus wingless, respectively); $0.99 \mathrm{mg}$ and $1.36 \mathrm{mg}$ for the orange adults (winged versus wingless, respectively)]. The green phenotype was heritable and robust when the aphids were kept at $8-10^{\circ} \mathrm{C}$ (Figure 1). Reversibility of the green phenotype back to orange was observed for all of the progeny without mortality when green mothers were placed back at $22^{\circ} \mathrm{C}$. The emerged progeny were immediately orange with no process of phenotypic selection. These results showed unambiguously that, at $22^{\circ} \mathrm{C}$, the pigments responsible for the green pigmentation are no longer synthesized and/or the corresponding enzymes 


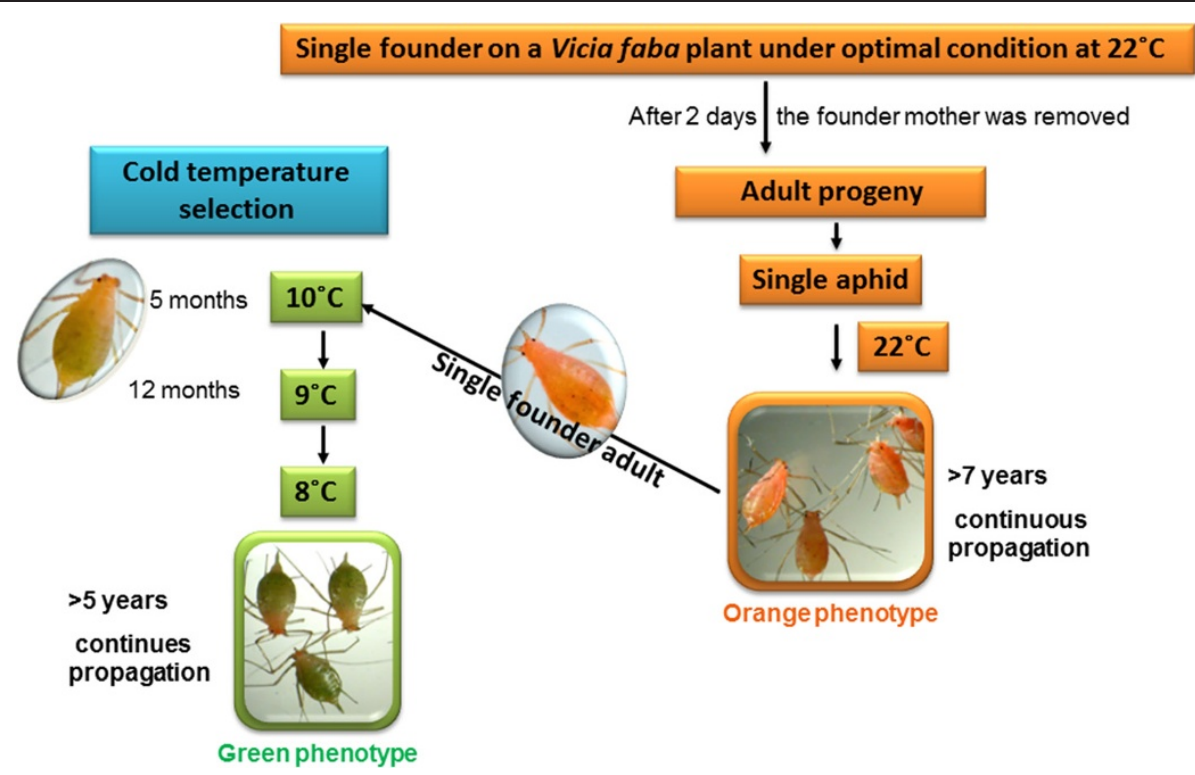

Figure 1 Selection process used to generate the green variant. Five to 10 orange adult Acyrthosiphon pisum (raised at $22^{\circ} \mathrm{C}$ ) were placed on Vicia faba plants kept at $10^{\circ} \mathrm{C}$. The aphid mothers were removed after 2 days, leaving the descendants. This process was repeated until a stable population emerged with a green phenotype (after 5 months). The original orange offspring did not reach maturation under these conditions. The population of cold-selected aphids with the green phenotype was propagated at $9^{\circ} \mathrm{C}$ for an additional year and then transferred to $8^{\circ} \mathrm{C}$ for continuous propagation (5 years).

are not induced. Genetic selection was observed during the passage from $22^{\circ} \mathrm{C}$ to $10^{\circ} \mathrm{C}$ and during the continued propagation at $9^{\circ} \mathrm{C}$, and was maintained at $8^{\circ} \mathrm{C}$. The enzymatic activity responsible for the change in color was inhibited when aphids were placed back at $22^{\circ} \mathrm{C}$.

\section{Adenine methylation at the GATC sites of the secondary endosymbiont is temperature-dependent}

Six fragments were selected (A1-A6) from the adeninemethylated amplification procedure (Figure 2, Additional file 1: Table S1). BLAST analyses of the nucleotide and deduced amino acid sequences of the six fragments did not reveal any match to the genomes of the $A$. pisum aphid or the primary endosymbiont $B$. aphidicola. However, the results indicated that the sequences belong to the pea aphid facultative endosymbiont $R$. insecticola or other potential endosymbionts, such as those belonging to the Yersinia genus-well-known facultative endosymbionts of mealybugs (Hemiptera, Coccoidea, Pseudococcidae) [32] that were also detected in the BLAST analyses (Additional file 1: Table S1).

The A1 fragment encoded a hypothetical $R$. insecticola protein with a high level of sequence similarity to the transposase of Microcystis aeruginosa and the IS4 transposase of Nostoc punctiforme. Further BLAST-X analysis of the A1 fragment revealed a conserved transposase domain within the sequence (helix-turn-helix of the DDE superfamily endonuclease). The A2 and A4 fragments matched hypothetical proteins belonging to the genera Regiella and Yersinia. The A3 fragment was highly similar to the secG subunit of a translocase involved in protein export. Like the $\mathrm{A} 1$ fragment (transposase), the A6 fragment was also found to be highly similar to enzyme involved in DNA rearrangement in the endosymbionts (Regiella and Yersinia), the helicase gene. The A6 helicase was identified as highly conserved among bacterial species with $94 \%$; $78 \%$ and $74 \%$ shared amino acid identity with $R$. insecticola, $Y$. enterocolitica and Salmonella enterica, respectively.

\section{Validation of adenine methylation at the GATC sites within the transposase gene}

To confirm the variability of adenine methylation between orange and green variants, fragments A1 and A6 were selected for further analysis. Based on the nucleotide sequence of $\mathrm{A} 1$ in the A. pisum EST database (accession number EST-CV840801), three putative GATC sites of potential adenine methylation were identified within and upstream of the original A1 sequence (marked as A1M1-A1M3 in Additional file 2: Figures S1 and Additional file 3: Figure S2a). The A1 fragment (including the extended sequence obtained from the NCBI database based on WP_002757529.1 and YP_001863818.1) was used in a subsequent comparative study of the green and orange aphid variants.

Genomic DNA (gDNA) was purified from orange and green adult aphids (42 individual aphids in total: 21 orange and 21 green-including 24 wingless and 18 winged 


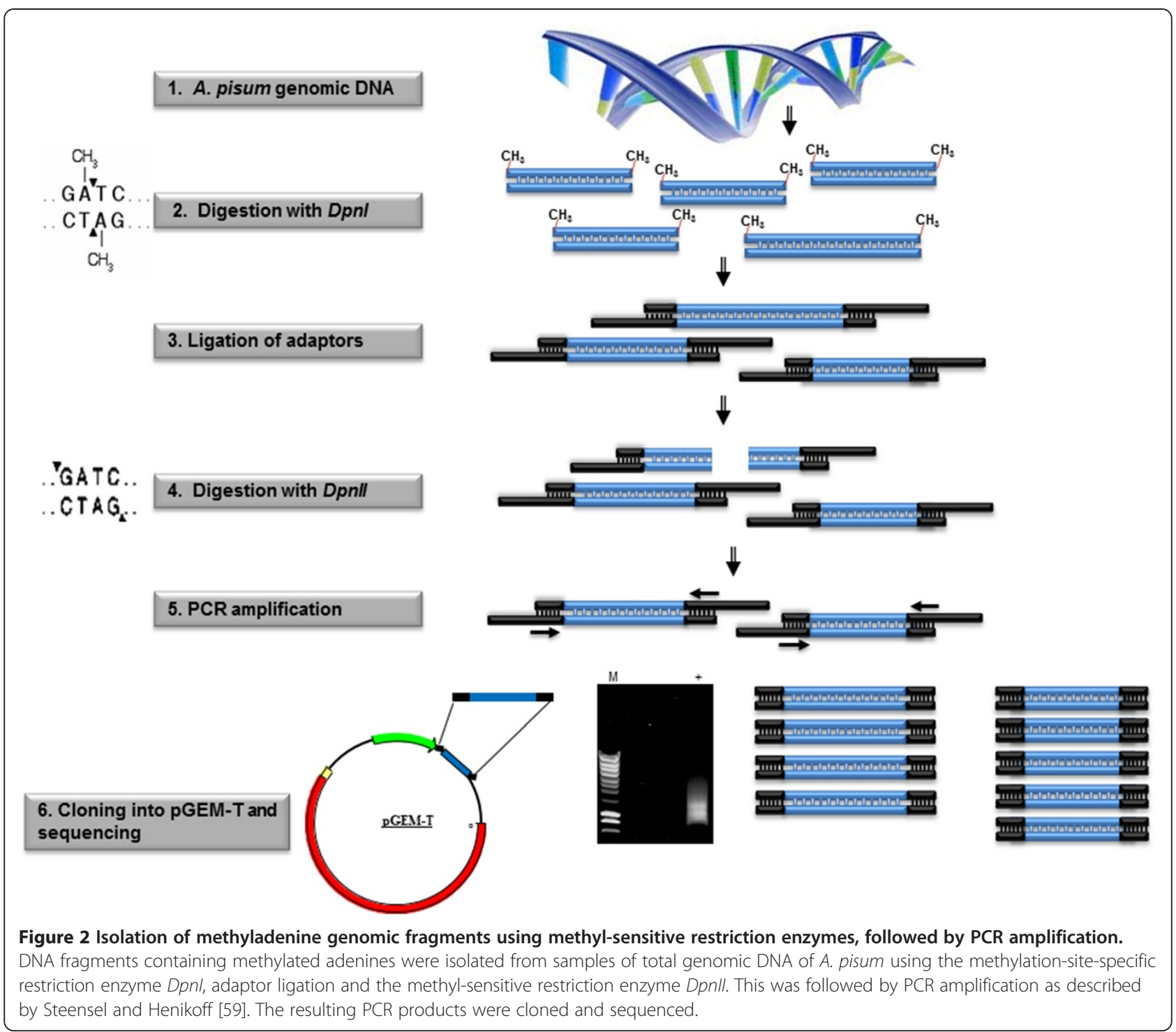

aphids) and subjected to pre-digestion with EcoRI (keeping the A1 fragment intact). Each gDNA sample was divided into three subsamples and subjected to a further Dam digestion series with the two restriction enzymes $D p n I$ and DpnII, separately and in combination. The digested gDNA served as a template for two PCR amplifications carried out using two primer pairs: A1F1, A1R1 (positive control, located downstream of the methylated site), and A1F2, A1R1, which flank the selected adenine-methylation site (A1M1; Figure 3a, Additional file 2: Figure S1).

For all 42 of the examined aphids (three samples of each-gDNA digested with DpnI, DpnII or a combination of the two), positive amplification was detected when the A1F1 and A1R1 primers were used in the PCR (positive control; Figure $3 \mathrm{~b}-\mathrm{c}$ ). However, no amplicons were detected when the primers A1F2 and A1R1 were used together with the DpnI-digested gDNA from 13 of the green aphids, and medium to low amplicon levels were detected for the other 8. Amplification was detected in all of the tested orange aphids: a high level of amplicons for 17 of these aphids and a medium level of amplicons for the other 4. For the samples subjected to DpnII digestion, strong amplification was detected among the samples from green aphids, whereas low to zero amplification was observed among the samples from orange aphids (Figure 3b-i; Table 1). Moreover, no differences were detected between the winged and wingless orange and green aphids (Figure 3b-i; Table 1). The pattern of adenine methylation was also examined for two additional GATC sites (A1M2 and A1M3) clustered upstream of the transposase gene in most of the examined aphids (Additional file 2: Figures S1 and Additional file 3: Figure S2). The differences observed in amplification intensity within the A1M1-A1M3 


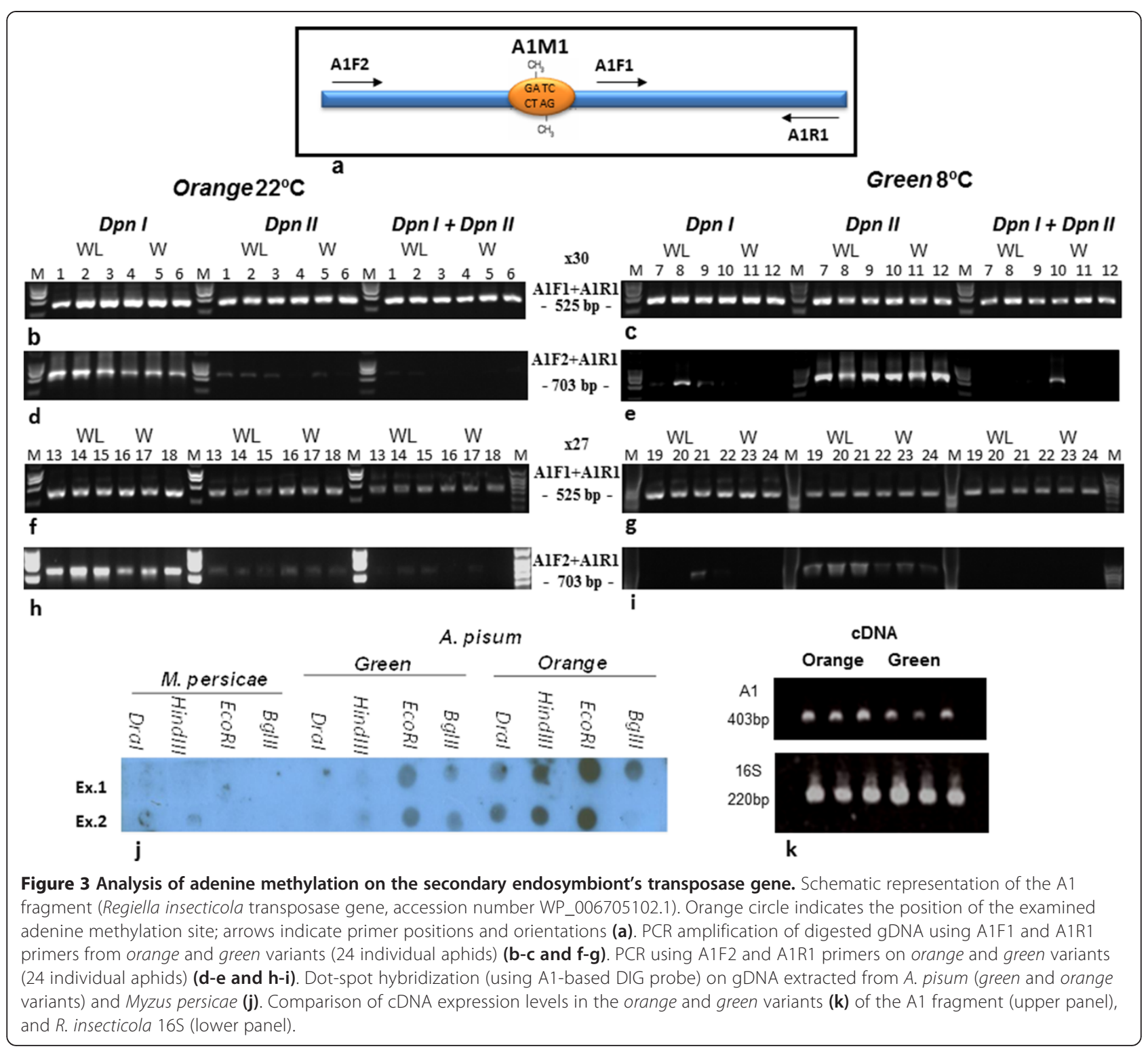

sites in the two variants were not influenced by the transposase transcript levels (Figure $3 \mathrm{k}$ ). Based on the Dam methylation amplification results, a clear pattern was detected that could be associated to the differences between the two aphid variants. However, to understand the causality and the mechanism involved, further study is required.
A digoxigenin (DIG) probe was used in dot-spot hybridization experiments to verify the presence of the A1 fragment (transposase) in gDNA obtained from $A$. pisum and Myzus persicae. The A1 DIG probe reacted specifically with the gDNA extracted from both orange and green variants of $A$. pisum, and failed to react with the gDNA of $M$. persicae (Figure $3 \mathrm{j}$ ).

Table 1 Summary of adenine methylation on the secondary endosymbiont's transposase gene

\begin{tabular}{|c|c|c|c|c|c|c|c|}
\hline \multirow{2}{*}{$\begin{array}{l}\text { Primers } \\
\text { Phenotype }\end{array}$} & \multirow[b]{2}{*}{${ }^{*}$ No. of aphids } & \multicolumn{3}{|c|}{$A 1 F \& A 1 R 1$} & \multicolumn{3}{|c|}{$A 1 F 2 \& A 1 R 1$} \\
\hline & & Dpnl & DpnII & $D p n I+D p n I I$ & Dpnl & Dpnll & Dpnl + Dpnll \\
\hline $22^{\circ} \mathrm{C}$ (Orange) & 21 & $(21)+++$ & $(21)+++$ & $(21)+++$ & $(17)+++(4)++$ & $(15)+(6)-$ & $(5)+(16)-$ \\
\hline $8^{\circ} \mathrm{C}$ (Green) & 21 & $(21)+++$ & $(21)+++$ & $(21)+++$ & $(3)++(5)+(13)-$ & $(13)+++(6)++(2)+$ & $(1)++(3)+(17)$ \\
\hline
\end{tabular}

*Number of individual Acyrthosiphon pisum aphids tested by PCR amplification. The amplicon intensity was categorized into three levels: +++, high; ++, medium; +low; - no amplification. 


\section{Genome rearrangement by transposase gene}

Two techniques-Southern blot and genome walkingwere adopted to confirm the differential genomic pattern mediated by the secondary endosymbiont transposase. The transposase assumed to be involved in genome rearrangement events leading to the establishment of new $A$. pisum variants.

A differential amplification pattern was observed upon comparison of the two A. pisum variants using transposasespecific primers (GW-F or GW-R) combined with a random hexamer primer $\left(\mathrm{N}_{5}\right)$ (Additional file 4: Figure S3a). Additional amplicons were detected in the green variant as compared to the orange variant (Additional file 4: Figure $\mathrm{S} 3 \mathrm{~b}$ ), demonstrating the possibility of transposase movement to a new location in the endosymbiont genome. For further validation, two additional PCRs were performed: first, with forward and reverse random hexamer primers (without the addition of the transposasespecific primer, as a negative control), which gave a negative result (Additional file 4: Figure S3c, left panel); second, with increased annealing temperature allowing for better specificity, and resulting in enhancement of the variation (Additional file 4: Figure S3c, right panel). Additional distinction between the two A. pisum variants was obtained by Southern blot analysis using digested gDNA from the two variants and a specific probe for the transposase. The hybridization pattern in the orange variant was located on fragments with relatively higher molecular weight relative to the green variant (Additional file 4: Figure S3d).

\section{Validation of adenine methylation at GATC sites within the helicase gene}

A sequence analysis similar to that described above for the A1 fragment was applied to the extended nucleotide sequence of the A6 fragment obtained from the $R$. insecticola genome (94\% identity; accession number WP_006705384.1). Three putative GATC sites were identified and further examined for adenine methylation (A6M1-A6M3; Figure 4a) using 12 A. pisum aphids (6 orange and 6 green). All tested aphids demonstrated a strong amplicon signal using A6F3 and A6R2 primers (positive control, no GATC site; Figure 4b-c and Table 2). Variation between the two aphid variants was detected

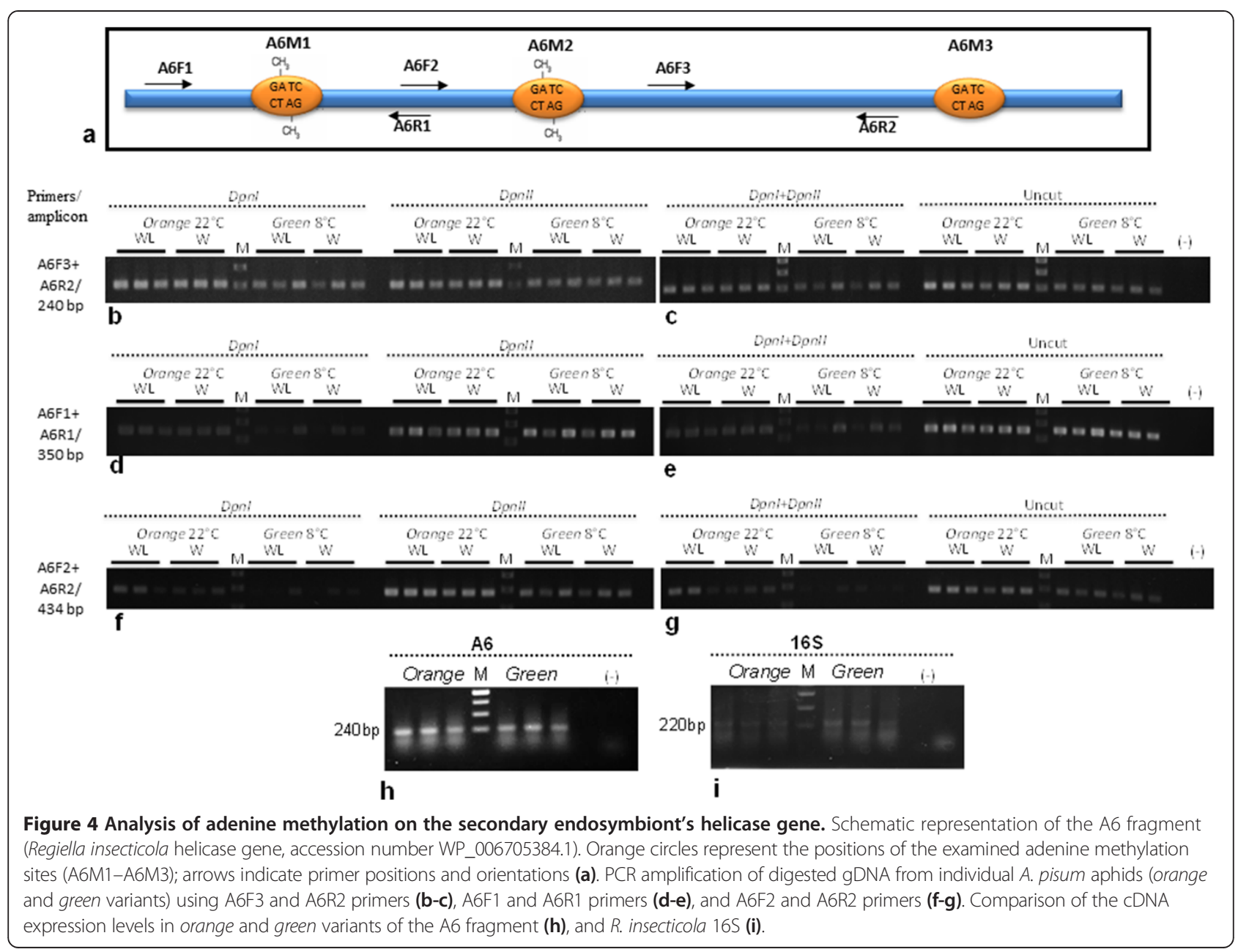


Table 2 Summary of the adenine methylation on the secondary endosymbiont's helicase gene

\begin{tabular}{|c|c|c|c|c|c|c|c|c|c|c|}
\hline \multirow{2}{*}{$\begin{array}{l}\text { Primers } \\
\text { Phenotype }\end{array}$} & \multirow[b]{2}{*}{${ }^{*}$ No. of aphids } & \multicolumn{3}{|c|}{ A6F3 \& A6R2 } & \multicolumn{3}{|c|}{ A6F1 \& A6R1 } & \multicolumn{3}{|c|}{$A 6 F 2 \& A 6 R 2$} \\
\hline & & $\overline{D p n l}$ & Dpnll & $\overline{D p n l+D p n I I}$ & Dpnl & Dpnll & $\overline{D p n l}+D p n I I$ & Dpnl & DpnII & $D p n l+D p n l l$ \\
\hline $22^{\circ} \mathrm{C}$ (Orange) & 6 & (6)+++ & (6) +++ & (6)+++ & (6) +++ & (6)+++ & (6) +++ & $(2)++(4)+$ & (6) +++ & $(2)++(4)+$ \\
\hline $8^{\circ} \mathrm{C}$ (Green) & 6 & (6) +++ & (6) +++ & $(6)++$ & (3) $++(2)+$ & (6)+++ & (3)++(3)+ & (3)++ & (6) +++ & $(2)+$ \\
\hline
\end{tabular}

*Number of individual Acyrthosiphon pisum aphids tested by PCR amplification. The amplicon intensity was categorized into three levels: +++, high; ++, medium; +low; -, no amplification.

within the A6M1 site by PCR amplification (using primers A6F1 and A6R1) of DpnI-digested DNA: strong amplicon intensity was obtained for the 6 orange aphids, whereas 5 green aphids demonstrated low to medium amplicon intensities, and no amplification was found for the 6th one (Figure 4d-e; Table 2). For the A6M2 site (A6F2 and A6R2 primers), medium to low amplification was detected for all 6 orange aphids, whereas medium amplification was detected for 3 green aphids and no amplification was detected for the other 3 (Figure 4f-g; Table 2). For the A6M3 site, high amplicon intensity with no variation was detected for the orange and green aphid variants (data not shown). The observed differences in adenine methylation on the A6M1 and A6M2 sites within the helicase gene were not related to gene expression (Figure $4 \mathrm{~h}-\mathrm{i}$ ).

\section{Discussion}

Selection of aphids toward cold adaptation, as reported in a previous study [3], allowed us to obtain a viable and robust colony of $A$. pisum with green abdomen morphology (green variant) at $8-10^{\circ} \mathrm{C}$ [3]. The physiological changes induced by cold temperature were correlated with dramatic variations in cuticular proteins expression [3]. Variation in cuticle pigmentation has been linked to the lateral transfer of carotenoid production genes from fungi to their aphid hosts [33]. Extensive comparisons of the carotene metabolism of three A. pisum variants that differ in their cuticle pigmentation have been made [31].

The heritability of the green phenotype at $8-10^{\circ} \mathrm{C}$ [3], and the higher adenine methylation rates within the transposase and helicase genes (current study), suggest the existence of a coincidental double mechanism: strain selection and the regulation of new active genes by adenine methylation.

The combinatorial effects of a few thousand secondary endosymbionts in a limited number of bacteriocytes constitute an ideal mechanism for lateral gene transfer, allowing selection and amplification of singular rearranged genomes [12,34]. This might support the assumption that the screening and selection process described by Dombrovsky et al. [3] recruited genes of endosymbiotic bacteria that are involved in host adaptation. These gene acquisitions, mediated by the temperature-dependent adenine methylation, might contribute to the 'epigenetic' regulation of unknown genes within the bacteria or the host genome.
In this study, we investigated the role of adenine methylation as an adaptive "on-off switch" [35] in endosymbiont bacteria, and whether this methylation is environmentally regulated in aphid endosymbionts and might thus be involved in the transition between orange and green phenotypes. Methylation at the N-6 position of adenine has been reported to be involved in many biological activities, from the control of chromosome replication and mismatch repair [36,37] to the regulation of transcription, gene expression and virulence [38] and triggering pathogenicity by the reversible expression of surface antigens on bacterial membranes [39-41].

The rapid disappearance of the green pigmentation from cold-selected green A. pisum variants at $22^{\circ} \mathrm{C}$ suggests that temperature-dependent mechanisms control adenine methylation/demethylation within the endosymbiont genes, such as those encoding transposase and helicase. Adenine methylation of these genes may affect additional genes related to cold adaptation and the accumulation/disappearance of green pigment. Helicase is a key enzyme in DNA replication [42,43] and mismatch repair $[44,45]$, which is mediated by adenine methylation in the bacterial genome $[37,44]$. Interestingly, cold adaptation of Bacillus subtilis has been reported to be mediated by RNA-helicase [37], although the role of adenine methylation in the DNA-helicase gene remains unknown.

A similar temperature-dependent phenomenon involving transposase activity in plants has been reported to be mediated by adenine methylation [46]. Moreover, transposases of the THAP (P transposase) superfamily have been shown to be involved in cellcycle regulation (in Caenorhabditis elegans [47] and different fish species [48]), epithelial cell regulation (in humans $[49,50])$ and the regulation of gene expression and plant development [51]. Transposases from this superfamily are also essential for the development of Oxytricha, a genus of ciliate protozoa, in which they appear to rearrange hundreds of thousands of DNA pieces to form functional rearranged genes. The organism inactivates the transposases when they are no longer required, resulting in a stable genome architecture [52]. Furthermore, a drastic effect of adenine methylation on transposase activity has been reported in Escherichia coli [53]. 
As in other organisms, transposase genes in the endosymbiont bacteria of aphids might also be involved in genome rearrangement. This mechanism might help minimize the time required for the host to adapt to new environmental conditions [54,55]. The transcription start time [35] and location of the transposase within the genome of the aphid endosymbiont bacteria might be controlled by adenine methylation within and upstream of the gene, as has been shown for other genes whose promoters exhibit Dam methylation $[37,53,56]$. Selective activation of the transposase within the bacteria may, in turn, affect the expression of essential genes and thereby contribute to the adaptation of the endosymbiont and its host to new environments, as described in this study for cold adaptation. More experiments should be performed in aphids to further evaluate the role of adenine methylation in transposases and other genes of secondary endosymbionts; this might be attained by high-throughput methods.

We can hypothesize that at least two methylation mechanisms coexist in aphids and provide epigeneticbased adaptive capabilities. The primary mechanism functions at the aphid genome level and involves the methylation of cytosine $[3,4,57,58]$. The secondary mechanism-the cooperative complementary mechanism described in this study-is based on the regulation of adenine methylation within "dynamic" endosymbiont genomes and enables the development of host aphid phenotypes that are adapted to a given environment. This paper suggests a theory in which the involvement of bacterial adenine methylation, as an 'epigenetic regulator', helps aphids adapt to extreme environmental conditions and host phenotypic diversity.

Our experimental data demonstrate that the selection of rare profiles in a repertoire of strains is correlated with adenine methylation of pre-selected key proteins, which have the potential to rearrange the endosymbiont genome and lead to the development of a viable and robust aphid phenotype in an unfavorable environment.

\section{Conclusion}

Our findings suggest that secondary endosymbionts contribute to aphid adaptation via the Dam mechanism. Regulation of adenine methylation within 'dynamic' endosymbiont genomes (e.g., transposase and helicase genes) is an additional mechanism assisting in aphid adaptation to a given environment which, in some cases, can be accompanied by a visible morphological phenotype. Transposase-mediated transposition may play a role in the multiple genetic and epigenetic mechanisms that together contribute to aphid phenotypic criteria and might act in concert to maximize host adaptation to unfavorable environmental conditions.

\section{Methods}

Maintenance and propagation of aphid species and variants Pea aphids (A. pisum) were maintained on Vicia faba plants grown in cages in a propagation chamber kept at $22 \pm 3^{\circ} \mathrm{C}$ and $60 \%$ relative humidity with a light/dark photoperiod of $16 / 8 \mathrm{~h}$. The selection of aphid variants at lower temperatures was carried out in an environmental test chamber (Sanyo, Bensenville, IL, USA) in which the temperature, humidity and photoperiod were kept at $8^{\circ} \mathrm{C}, 60 \%$ and $16 \mathrm{~h}$ light $/ 8 \mathrm{~h}$ dark, respectively. The green peach aphid $M$. persicae (Sulzer) was raised on mustard plants (Brassica perviridis cv. Tendergreen) in a greenhouse kept at $25 \pm 3^{\circ} \mathrm{C}$.

\section{Phenotypic selection at cold temperatures}

Five to ten adult orange aphids (raised at $22^{\circ} \mathrm{C}$ ) were placed in a container kept at $10^{\circ} \mathrm{C}$ and the founder aphids were removed after 2 days. This process was repeated for 5 months, until a stable and robust population with a green abdomen phenotype was established. The population of cold-selected aphids (green phenotype) was propagated at $9^{\circ} \mathrm{C}$ for an additional year and the ambient temperature was then lowered to $8^{\circ} \mathrm{C}$ for continuous propagation ( $>5$ years) (Figure 1$)$.

\section{Detection of methyl-adenine}

Adenine-methylated DNA fragments were isolated from $A$. pisum gDNA (green variants). The fragments were identified and isolated using a pair of restriction enzymes recognizing the same nucleotide sequence (GATC): the first, DpnI, digests while the adenine is methylated; the second, DpnII, is blocked by the presence of a methyl group on the adenine. This procedure is described in detail in Figure 2. Briefly, gDNA was extracted from $100 \mathrm{mg}$ of $A$. pisum (green and orange variants) using the DNeasy Plant Mini Kit (Qiagen, Hilden, Germany). DNA fragments containing methylated adenines were isolated from the genomic DNA using the methylation-specific restriction enzyme $D p n I$ together with the methyl-sensitive restriction enzyme DpnII (New England Biolabs, Ipswich, MA, USA). The digested fragments were ligated to the adaptors:

AdRt (5'-CTAATACGACTCACTATAGGGCAGCGTG GTCGCGGCCGAGGA-3') and AdRb (5'-TCCTCGGCC G-3'). This was followed by PCR amplification using AdR_PCR (5'-GGTCGCGGCCGAGGATC-3'), as described previously [59]. The resulting PCR products were cloned into pGEM-T Easy (Promega, Madison, WI, USA) and sequenced from both directions (T7 and SP6) (Figure 2).

\section{Detection of adenine methylation within the transposase gene obtained from an individual aphid}

Total DNA was extracted from individual A. pisum aphids (Qiagen) propagated at $20^{\circ} \mathrm{C}$ (orange variant) or 
$8^{\circ} \mathrm{C}$ (green variant). The obtained gDNA was pre-digested with EcoRI and then re-digested with DpnI, DpnII or a combination of the two enzymes (each reaction performed separately). The digested gDNA was then PCR-amplified using two pairs of primers: A1R1 (5'-TGTCATGACGTC GACCATTT-3') paired with the primers A1F1 (5'-TA GTGGGGCTATCGTTGGAA-3'), A1F2 (5' -TTTAAGAT TCCGCCTGGTTG-3') and A1F3 (5'-GATTATCATGG CAGCGCATA-3'), which were designed for the transposase gene (Figure 3a).

Expression differences between the orange and green variants were examined by extracting total RNA from single aphids. This RNA $(50 \mu \mathrm{l})$ served as the template for cDNA synthesis using oligo-dt and random hexamer as the reverse primer. The cDNA was later amplified for 26 cycles using a specific primer set for the coding region of the transposase gene (as forward primer: $5^{\prime}$ TTTTTACCAACCCCATTGGA-3' and reverse primer R1) and the $16 \mathrm{~S}$ gene (as forward primer: $5^{\prime}$-ATCGGG GAGTAGCTTGCTAC-3' and reverse primer: 5'-CTA GAGATCGTCGCCTAGGTA-3') belonging to Regiella.

\section{Detection of adenine methylation within the helicase gene obtained from an individual aphid}

Total DNA from 24 A pisum aphids (12 from each variant-orange and green) was extracted and treated as described above. The digested DNA was PCR-amplified using three primer sets: for a positive control amplification (including no restriction sites), A6F3 (5'-TTGCATGA ACCCATGACATT-3') and A6R2 (5'-AATGCCGACA TAAGCCAAAC- $3^{\prime}$ ) were used to amplify the 240-bp amplicon. For the detection of methylation on site A6M1, A6F1 (5'-GTATCGAGGAAATCACCAAGC-3') and A6R1 (5'-GCATAATTTCTGCCATCCAG-3') were used to amplify the 350-bp amplicon; and for the detection of methylation on site A6M2, A6F2 (5'-TTACT CACTGGATGGCAGAAA-3') and A6R2 were used to amplify the 434-bp amplicon (Figure 4a).

\section{Genome walking for transposase gene}

To examine the possible occurrence of genome rearrangement, a 'genome walking' strategy was selected. Briefly, EcoRI- and BamHI-digested gDNA extracted from green and orange variants served as the templates for PCR amplification using a single specific primer located at the extremities of the extended A1 fragment (transposase gene) (GW-F: 5' -AGTGGGTTTTCTCTCACTGAGT-3' or GW-R: 5'-CAACCAGGCGGAAT CTTAAAC-3') combined with a random hexamer primer (Additional file 4: Figure S3a). The reaction conditions were as follows: $95^{\circ} \mathrm{C}$ for 2 min followed by 35 cycles of $95^{\circ} \mathrm{C}$ for $30 \mathrm{~s}, 42^{\circ} \mathrm{C}$ for $30 \mathrm{~s}, 72^{\circ} \mathrm{C}$ for $1.5 \mathrm{~min}$ and a final elongation at $72^{\circ} \mathrm{C}$ for $5 \mathrm{~min}$. The resultant PCR products were separated on a $1 \%$ agarose gel and selected fragments were cloned into pGEM-T Easy followed by nucleotide sequencing. Additional PCRs were carried out by increasing the annealing temperature ( 5 cycles at $42^{\circ} \mathrm{C}$ and 30 cycles at $50^{\circ} \mathrm{C}$ ), and a negative control on the digested gDNA using random hexamer solely.

\section{DIG labeling and hybridization}

Part of the A1 fragment (400 bp, transposase gene) was used for probe preparation. DIG-labeled nucleotides were introduced into the probe by PCR amplification. The reaction mixture contained the forward primer A1F1, the complementary primer A1R1 and a dNTP mixture containing DIG-labeled dUTP (2 mM dATP, dCTP, dGTP, $1.3 \mathrm{mM}$ dTTP and $0.7 \mathrm{mM}$ alkali labile DIG-11 dUTP), 100 pM DNA template and 1.5 units of Dream Taq polymerase (Fermentas-Thermo Fisher Scientific, Burlington, Canada).

\section{Dot blot}

Each gDNA sample (two gDNA samples from each of the following: $M$. persicae and the orange and green variants of $A$. pisum) was digested separately with four restriction enzymes (BglII, EcoRI, DraI and HindIII). A $2-\mu$ l aliquot (100 ng) of each sample was blotted on a positively charged membrane (Roche, Basel, Switzerland) and then cross-linked under UV for $3 \mathrm{~min}$.

\section{Southern blot}

Samples $(5 \mu \mathrm{g})$ of gDNA extracted from orange and green variants were digested with EcoRI and BamHI and separated on a $0.7 \%$ agarose gel. Then transferred to a positively charged membrane and cross-linked under UV.

Both membranes were pre-hybridized at $50^{\circ} \mathrm{C}$ in DIG Easy Hyb solution (Roche). Hybridization was performed at $50^{\circ} \mathrm{C}$ overnight followed by a high-stringency wash. A CSPD chemifluorescence kit (Roche) was used to detect the probe signal on X-ray film.

\section{Additional files}

Additional file 1: Table S1. Sequences and BLAST results for the

adenine methylated fragments.

Additional file 2: Figure S1. The nucleotides sequence and amino acid prediction of the aphid Transposase gene (A1 fragment) The DNA fragment (A1) was isolated from A. pisum based on methylation of adenine. (a) The nucleotide sequence of the original DNA fragment and the deduced amino acid encodes for a transposase gene. The translated sequence matches the transposase of: Microcystis aeruginosa (accession number WP_002757529.1) and Nostoc punctiforme (accession number YP_001863818.1). In gray the two putative sites for methylation on adenine flanking the region. (b) The EST-CV840801, represents a DNA fragment from the A. pisum EST data bank that shows high sequence similarity to the A1 DNA fragments. The upper lines are the nucleotide sequence encoding for transposase, and below is the deduced amino-acid residues. In bold, the transposase coding region. Mark in gray, the three putative sites for methylation on adenine that were 
identified upstream to the transposase gene. The primers sequences underlined and labeled in bold.

Additional file 3: Figure S2. Extended analysis of adenine methylation in the transposase gene. Total DNA was extracted from each individual $A$ pisum aphid propagated at $20^{\circ} \mathrm{C}$ (orange variant, lanes $1-3$ ) or at $8^{\circ} \mathrm{C}$ (green variant, lanes 4-6). The obtained gDNA was pre-digested with EcoRl, and then re-digested by Dpnl, Dpnll or both. (a) Schematic representation of the extended A1 fragment (transposase gene). Orange circles represent the potential adenine methylation sites and arrows indicate the primers positions. The digested gDNA was amplified by PCR using three pairs of primer: A1R1 combined with (b) A1F1, (c) A1F2 or (d) A1F3.

Additional file 4: Figure S3. Genome rearrangement. (a) Schematic representation of the extended $\mathrm{A} 1$ fragment (transposase gene) and the method used. Restriction enzymes indicated at the top, arrows indicates primer position and orientation. Orange circles represent the potential adenine methylation sites (A1M1-A1M3). (b) Differential amplification pattern on digested gDNA obtained from orange $(\mathrm{O})$ and green $(\mathrm{G})$ aphids. PCRs carried out using singular transposase specific primer [GW-F (left panel) or GW-R (right panel)] combined with random hexamer $\left(\mathrm{N}_{5}\right)$, $(-)$ indicates negative control, without template. (c) Controls: random hexamer solely (left panel) and increasing the annealing temperature in order to increase the specificity of the transposase specific primer (right panel). (d) Southern blot analysis on orange or green aphid variants digested gDNA (EcoRI or BamHI), the transposase DIG-probe (400 bp) reacted positively with the unlabeled amplicon (positive control, right lane).

\section{Competing interests}

The authors declare that they have no competing interests.

\section{Authors' contributions}

$A D$ and $A R$ designed and interpreted the experiments. AD, VR and NL performed the experiments. $A D$ and VR wrote the manuscript. All authors read and approved the final manuscript.

\section{Acknowledgments}

We thank the Baylor College of Medicine for allowing open access to the $A$. pisum genome database. This work was supported by an ANR grant "exsidum" and a postdoctoral fellowship from Ministère de la Recherche et Enseignement Supérieur to AD, and a Ph.D. fellowship from the Signalife LabEx program of Nice University to VR.

Received: 10 April 2014 Accepted: 4 November 2014

Published: 19 November 2014

\section{References}

1. Brisson JA, Stern DL: The pea aphid, Acyrthosiphon pisum: an emerging genomic model system for ecological, developmental and evolutionary studies. Bioessays 2006, 28(7):747-755.

2. Consortium IAG: Genome sequence of the pea aphid Acyrthosiphon pisum. PLoS Biol 2010, 8(2):e1000313.

3. Dombrovsky A, Arthaud L, Ledger TN, Tares S, Robichon A: Profiling the repertoire of phenotypes influenced by environmental cues that occur during asexual reproduction. Genome Res 2009, 19(11):2052-2063.

4. Walsh TK, Brisson JA, Robertson HM, Gordon K, Jaubert-Possamai S, Tagu D, Edwards OR: A functional DNA methylation system in the pea aphid, Acyrthosiphon pisum. Insect Mol Biol 2010, 19(Suppl 2):215-228.

5. Moran N, Wernegreen J: Lifestyle evolution in symbiotic bacteria: insights from genomics. Trends Ecol Evol 2000, 15(8):321-326.

6. Sandstrom JP, Russell JA, White JP, Moran NA: Independent origins and horizontal transfer of bacterial symbionts of aphids. Mol Ecol 2001, 10(1):217-228

7. Moran NA, Telang A: Bacteriocyte-associated symbionts of insects - a variety of insect groups harbor ancient prokaryotic endosymbionts. Bioscience 1998, 48(4):295-304.

8. Moran NA, Baumann P: Bacterial endosymbionts in animals. Curr Opin Microbiol 2000, 3(3):270-275.

9. Shigenobu S, Wilson AC: Genomic revelations of a mutualism: the pea aphid and its obligate bacterial symbiont. Cell Mol Life Sci 2011, 68(8):1297-1309.
10. Moran NA, Plague GR, Sandstrom JP, Wilcox JL: A genomic perspective on nutrient provisioning by bacterial symbionts of insects. Proc Natl Acad Sci U S A 2003, 100(Suppl 2):14543-14548.

11. Brinza L, Vinuelas J, Cottret L, Calevro F, Rahbe Y, Febvay G, Duport G, Colella S, Rabatel A, Gautier C, Fayard JM, Sagot MF, Charles H: Systemic analysis of the symbiotic function of Buchnera aphidicola, the primary endosymbiont of the pea aphid Acyrthosiphon pisum. C R Biol 2009, 332(11):1034-1049.

12. Braendle C, Miura T, Bickel R, Shingleton AW, Kambhampati S, Stern DL: Developmental origin and evolution of bacteriocytes in the aphid-Buchnera symbiosis. PLOS Biol 2003, 1(1):E21

13. Dale C, Moran NA: Molecular interactions between bacterial symbionts and their hosts. Cell 2006, 126(3):453-465.

14. Baumann P, Baumann L, Lai CY, Rouhbakhsh D, Moran NA, Clark MA: Genetics, physiology, and evolutionary relationships of the genus Buchnera: intracellular symbionts of aphids. Annu Rev Microbio/ 1995 49:55-94.

15. Tamas I, Klasson L, Canback B, Naslund AK, Eriksson AS, Wernegreen Jر, Sandstrom JP, Moran NA, Andersson SG: 50 million years of genomic stasis in endosymbiotic bacteria. Science 2002, 296(5577):2376-2379.

16. Scarborough CL, Ferrari J, Godfray HCJ: Aphid protected from pathogen by endosymbiont. Science 2005, 310(5755):1781.

17. Oliver KM, Russell JA, Moran NA, Hunter MS: Facultative bacterial symbionts in aphids confer resistance to parasitic wasps. Proc Natl Acad Sci U S A 2003 100(4):1803-1807.

18. Montllor $\mathrm{CB}$, Maxmen A, Purcell AH: Facultative bacterial endosymbionts benefit pea aphids Acyrthosiphon pisum under heat stress. Ecol Entomol 2002, 27:189-195.

19. Tsuchida T, Koga R, Fukatsu T: Host plant specialization governed by facultative symbiont. Science 2004, 303(5666):1989.

20. Muller CB, Williams IS, Hardie J: The role of nutrition, crowding and interspecific interactions in the development of winged aphids. Ecol Entomol 2001, 26(3):330-340.

21. Leonardo TE, Mondor EB: Symbiont modifies host life-history traits that affect gene flow. Proc Bio/ Sci 2006, 273(1590):1079-1084.

22. Miura $T$, Braendle $C$, Shingleton A, Sisk G, Kambhampati S, Stern DL: A comparison of parthenogenetic and sexual embryogenesis of the pea aphid Acyrthosiphon pisum (Hemiptera: Aphidoidea). J Exp Zool B Mol Dev Evol 2003, 295B(1):59-81

23. Tsuchida T, Koga R, Horikawa M, Tsunoda T, Maoka T, Matsumoto S, Simon J-C, Fukatsu T: Symbiotic bacterium modifies aphid body color. Science 2010, 330(6007):1102-1104

24. Perez-Brocal V, Gil R, Ramos S, Lamelas A, Postigo M, Michelena JM, Silva FJ, Moya A, Latorre A: A small microbial genome: the end of a long symbiotic relationship? Science 2006, 314(5797):312-313.

25. Anderson JO, Anderson SGE: Insights into the evolutionary process of genome degradation. Curr Opin Genet Dev 1999, 9:664-671.

26. van der Wilk F, Dullemans AM, Verbeek M, van den Heuvel JF: Isolation and characterization of APSE-1, a bacteriophage infecting the secondary endosymbiont of Acyrthosiphon pisum. Virology 1999, 262(1):104-113.

27. Kleckner N: Transposable elements in prokaryotes. Annu Rev Genet 1981, 15:341-404.

28. Hentschel U, Steinert M, Hacker J: Common molecular mechanisms of symbiosis and pathogenesis. Trends Microbiol 2000, 8(5):226-231.

29. Bordenstein SR, Reznikoff WS: Mobile DNA in obligate intracellular bacteria. Nat Rev Microbio/ 2005, 3(9):688-699.

30. Mazel D: Integrons: agents of bacterial evolution. Nat Rev Microbiol 2006, 4(8):608-620.

31. Valmalette JC, Dombrovsky A, Brat P, Mertz C, Capovilla M, Robichon A: Light- induced electron transfer and ATP synthesis in a carotene synthesizing insect. Sci Rep 2012, 2:579

32. Thao ML, Gullan PJ, Baumann P: Secondary (gamma-Proteobacteria) endosymbionts infect the primary (beta-Proteobacteria) endosymbionts of mealybugs multiple times and coevolve with their hosts. Appl Environ Microbiol 2002, 68(7):3190-3197.

33. Moran NA, Jarvik T: Lateral transfer of genes from fungi underlies carotenoid production in aphids. Science 2010, 328(5978):624-627.

34. Nikoh N, Nakabachi A: Aphids acquired symbiotic genes via lateral gene transfer. BMC Biol 2009, 7:12

35. Low DA, Casadesus J: Clocks and switches: bacterial gene regulation by DNA adenine methylation. Curr Opin Microbiol 2008, 11(2):106-112. 
36. Ogden GB, Pratt MJ, Schaechter M: The replicative origin of the E. coli chromosome binds to cell membranes only when hemimethylated. Cell 1988, 54(1):127-135.

37. Marinus MG, Casadesus J: Roles of DNA adenine methylation in host-pathogen interactions: mismatch repair, transcriptional regulation, and more. FEMS Microbiol Rev 2009, 33(3):488-503.

38. Low DA, Weyand NJ, Mahan MJ: Roles of DNA adenine methylation in regulating bacterial gene expression and virulence. Infect Immun 2001, 69(12):7197-7204

39. Palmer BR, Marinus MG: The dam and dem strains of Escherichia coli-a review. Gene 1994, 143(1):1-12

40. Wion D, Casadesus J: N6-methyl-adenine: an epigenetic signal for DNA-protein interactions. Nat Rev Microbio/ 2006, 4(3):183-192.

41. Noyer-Weidner M, Trautner TA: Methylation of DNA in prokaryotes. EXS 1993, 64:39-108.

42. Alberts BM: Prokaryotic DNA-replication mechanisms. Philos Trans R SoC Lond B Biol Sci 1987, 317(1187):395-420.

43. Marians KJ: Prokaryotic DNA-replication. Annu Rev Biochem 1992, 61:673-719.

44. Barras F, Marinus MG: The great Gatc - DNA methylation in Escherichia-coli. Trends Genet 1989, 5(5):139-143.

45. Wu L, Hickson ID: DNA helicases required for homologous recombination and repair of damaged replication forks. Annu Rev Genet 2006, 40:279-306.

46. Hashida SN, Uchiyama T, Martin C, Kishima Y, Sano Y, Mikami T: The temperature-dependent change in methylation of the Antirrhinum transposon Tam3 is controlled by the activity of its transposase. Plant Cell 2006, 18(1):104-118.

47. Boxem M, van den Heuvel S: C. elegans class B synthetic multivulva genes act in G (1) regulation. Curr Biol 2002, 12(11):906-911.

48. Giangrande PH, Zhu W, Schlisio S, Sun X, Mori S, Gaubatz S, Nevins JR: A role for E2F6 in distinguishing G1/S- and G2/M-specific transcription. Genes Dev 2004, 18(23):2941-2951.

49. Cayrol C, Lacroix C, Mathe C, Ecochard V, Ceribelli M, Loreau E, Lazar V, Dessen P, Mantovani R, Aguilar L, Girard JP: The THAP-zinc finger protein THAP1 regulates endothelial cell proliferation through modulation of pRB/E2F cell-cycle target genes. Blood 2007, 109(2):584-594.

50. Sinzelle L, Izsvak Z, Ivics Z: Molecular domestication of transposable elements: from detrimental parasites to useful host genes. Cell Mol Life Sci 2009, 66(6):1073-1093.

51. Bundock P, Hooykaas P: An Arabidopsis hAT-like transposase is essential for plant development. Nature 2005, 436(7048):282-284.

52. Nowacki M, Higgins BP, Maquilan GM, Swart EC, Doak TG, Landweber LF: A functional role for transposases in a large eukaryotic genome. Science 2009, 324(5929):935-938.

53. Roberts D, Hoopes BC, McClure WR, Kleckner N: IS10 transposition is regulated by DNA adenine methylation. Cell 1985, 43(1):117-130

54. Top EM, Springael D: The role of mobile genetic elements in bacterial adaptation to xenobiotic organic compounds. Curr Opin Biotechnol 2003, 14(3):262-269.

55. Blot M: Transposable elements and adaptation of host bacteria. Genetica 1994, 93(1-3):5-12.

56. Kucherer $\mathrm{C}$, Lother $\mathrm{H}$, Kolling R, Schauzu MA, Messer W: Regulation of transcription of the chromosomal dnaA gene of Escherichia coli. Mol Gen Genet 1986, 205(1):115-121.

57. Field LM: Methylation and expression of amplified esterase genes in the aphid Myzus persicae (Sulzer). Biochem J 2000, 349(Pt 3):863-868.

58. Field LM, Lyko F, Mandrioli M, Prantera G: DNA methylation in insects. Insect Mol Biol 2004, 13(2):109-115.

59. van Steensel B, Henikoff S: Identification of in vivo DNA targets of chromatin proteins using tethered dam methyltransferase. Nat Biotechnol 2000, 18(4):424-428.

\section{doi:10.1186/1471-2164-15-999}

Cite this article as: Reingold et al.: Adenine methylation may contribute to endosymbiont selection in a clonal aphid population. BMC Genomics 2014 15:999.

\section{Submit your next manuscript to BioMed Central and take full advantage of:}

- Convenient online submission

- Thorough peer review

- No space constraints or color figure charges

- Immediate publication on acceptance

- Inclusion in PubMed, CAS, Scopus and Google Scholar

- Research which is freely available for redistribution

Submit your manuscript at www.biomedcentral.com/submit
C BioMed Central 